\title{
The growth of flower bud, life history, and population structure of Rafflesia arnoldii (Rafflesiaceae) in Bengkulu, Sumatra, Indonesia
}

\author{
AGUS SUSATYA \\ Department of Forestry, Faculty of Agriculture, Universitas Bengkulu. Jl. Raya Kandang Limun, Bengkulu 38371, Indonesia. \\ Tel./Fax. +62-736-21170. `email: agussusatya @gmail.com
}

Manuscript received: 1 October 2019. Revision accepted: 27 January 2020.

\begin{abstract}
Susatya A. 2020. The growth of flower bud, life history, and population structure of Rafflesia arnoldii (Rafflesiaceae) in Bengkulu, Sumatra, Indonesia. Biodiversitas 21: 792-798. The life history of Rafflesia arnoldii R.Br. is the reflection of the complex interaction between flower bud development and the external environments in order to reach its optimal survivorship. The objectives of the study were to determine the growth of flower buds at various development stages, to reconstruct the life history, and to know the population structure of $R$. arnoldii. The study was carried out at Taba Penanjung, Bengkulu Province, Indonesia. Two populations consisting of 17 individual buds of $R$. arnoldii were selected for the research. All buds were categorized into six visible stages, mapped, measured their diameters, and recorded their fates every two weeks for six months. The exponential model of growth development was applied to reconstruct the life history. The results showed that buds from the perigone stage respectively grew 3.5 and 12 times faster than those from the bract and cupule stages. The exponential growth of flower bud was confirmed, and explained by $\mathrm{Y}=0.785 \mathrm{e}^{0.0052 \mathrm{X}}$, where $\mathrm{Y}$ and $\mathrm{X}$ were respectively diameter and age of flower bud. The complete life history of $R$. arnoldii required 3.5 to 5 years, where a female flower needed a longer time than a male flower. The population structure of $R$. arnoldii was not constant, but changed dynamically over time. The dynamics of population structure was mainly caused by the high mortality of small buds and the low flower bud recruitment.
\end{abstract}

Keywords: Copule, exponential, perigone, population, Rafflesia arnoldii

\section{INTRODUCTION}

Life history or life cycle of plants is generally referred to the dynamics of entire growth stages of plants to adapt to surrounding environments (Lime 2017). Life history involves complex responses of plants to environments acting as natural selection. Such plant-environment interaction leads to plants to develop the trade-off strategies between their functional traits such as plant's statures, leaf area, wood density, seed productions and their demographic attributes including growth rates and survivorships to cope the environmental pressures (Lind et al.2013; Liu et al.2017). The ultimate goal of the strategies is to reach the plant's maximum fitness (Lind et al.2013). The fitness itself reflects the growth and mortality rates at different development stages (Crawley 1986), reproduction, fecundity, new recruitment, and the energy allocated to reproduction (Smith 1986). Furthermore, the growth rate appeared to affect the survival of seedlings of Calathea ovandensis, a neotropical herb (Horvits and Schemske 2002). The development stage, which was expressed by the plant's size, apparently also influenced mortality. Advanced development stages or larger plants tended to have a lower mortality (Wunder at al. 2008). Moreover, the inability plant to cope with the environmental pressures at various stages could lead to the failure of the plants to survive (Wunder et al. 2008).

Rafflesia arnoldii R.Br. (Rafflesiaceae) is well known as the biggest single flower among the plant kingdom. It is a holoparasitic plant, which its life entirely depends on its hosts consisting of Tetrastigma leucostaphyllum (Dennst.) Alston ex Mabb., T.curtisii (Ridl) Suess, T. pedunculare (Wall. ex. Lamson) Planch (Vitaceae) (Meijer 1997; Zuhud et al. 1998; Susatya 2011). It has unique biological characteristics such as trunkless, leafless, and no true root system. The only visible organ is a flower (Mat-Salleh 1991; Meijer 1997; Nais 2001). Such characteristics could lead to an interesting pattern of its life history. Unfortunately, the life history of species of Rafflesia was rarely studied, because of the length of its life history, relatively small population, high mortality, the uncertainty of a single bud to reach maturity, and the remoteness of its location (Nais 2001; Hidayati and Walck 2016). Among 36 recognized species of Rafflesia (Hidayati and Walck 2016), a detailed life history was only provided by Hidayati et al. (2000) for R. patma Blume, and Nais (2001) for R. keithii Meijer, $R$. pricei Meijer, and $R$. tengku-adlinii Mat-Salleh \& Latiff. It required 256 to 512 days for $R$. patma, (Hidayati et al. 2000), 270 to 390 days for $R$. tengkuadlinii, 300 to 450 days for $R$. pricei, and 360-480 days for $R$. keithii (Nais 2001) to complete its respective life history. Both Hidayati et al. (2000) and Nais (2001) further divided the life history of Rafflesia species into 7 sequential development stages, and estimated time required to reach each stage. The stages included pollination, fruit and seed formation, seed dispersal, inoculation its seeds to the host, the emergence of flower bud, mature bud, and anthesis (Hidayati et al. 2000; Nais 2001). Basically, the life history 
of Rafflesia can be divided into invisible and visible stages. The former includes the growth of Rafflesia's seed inside its host plant, which can take 2-3 years (Hidayati et al. 2000), the latter consists of several flower bud developments. The visible one is also the only structure that is exposed to external environments. Due to the combination of the exposure of the various external environments and various flower bud sizes, it is expected that the different bud sizes will show different growth rates (Hidayati et al. 2000), and mortality rate (Susatya et al. 2017).

The main objectives of this research were to reconstruct the life history according to flower development stages, and to determine the growth and mortality rate of the flower buds, and to know the change of the population structure of $R$. arnoldii over time according to its flower development stages.

\section{MATERIALS AND METHODS}

\section{Study area}

The research site was located in Taba Penanjung Conservation Area (TPCA) within Bukit Daun Protection Forest, Central Bengkulu, Bengkulu Province, Indonesia, with coordinates between $3^{0} 41^{\prime} 42.00$ "S and $102^{0} 32^{\prime} 0.100^{\prime}$ 'E. TPCA was established to protect 4 populations of $R$. arnoldii, however, two of them were perished due to their host plants was cut down. Data from the nearest climate station of Kepahiang Regency showed that the site received an average of the annual rainfall of $2.717 \mathrm{~mm}$. Meanwhile, the average monthly rainfall reached 226 mm (BPS Kab. Kepahiang 2018).

\section{Plant materials and procedures}

To carry out the study, two populations from two different host plants consisting of 17 flower buds were observed their buds every two weeks for six months. Each bud was recorded its coordinate, mapped and labeled, vertically photographed and measured its diameter at every observation. For the life history study, the observation was limited to Rafflesia's visible structure, flower buds. Furthermore, the flower bud development stage of $R$. arnoldii was grouped according to the combination of the size of buds (Hidayati et al. 2000; Sofiyanti et al. 2007) and the morphology of $R$. arnoldii. Based on these two criteria, the life history was then more detailedly categorized into eight stages consisting of six visible flower development stages, mature fruit, and one an invisible stage. The invisible stage included inoculation and seed germination processes within its host. The visible stage contained copule, copule-bract transition (CBT), bract, bract-perigone transition (BPT), perigone, and anthesis stages (Figure 1).



Figure 1. The flower development stage of Rafflesia arnoldii. A. Copule stage. B. Copule-bract transition stage, CBT. In CBT, parts of copule (cp) are still largely seen, and gradually replaced by bracts (br). C. Bract stage, a stage where a visible bud is fully covered by bract, a similar structure to sepal. D. Bract-perigone transition stage, BPT, a stage where bracts are still largely recognized (br) and gradually replaced by perigones (pr). E. Perigone stage. A visible bud at this stage is all covered by perigone, a similar structure to petal. F. Anthesis stage. 


\section{Data analysis}

To categorize a bud into a certain stage, each bud was vertically photographed. Copule, bract, and perigone stages were defined by the $80-100 \%$ of the images of vertically photographed bud respectively covered by copule, bract, and perigone structures. A bud was categorized into CBT, if it grew between copule and bract stages, and the coverage of the images of the photographed bud by bract reached $40 \%$ to $80 \%$. Meanwhile, a bud was grouped into BPT, if it grew between bract and perigone stages with the coverage of the images of the photographed bud by perigone reaching to $40 \%$ to $80 \%$. Any bud had less $40 \%$ of the coverage by either bract or perigone, was also respectively categorized into either copule or bract stages. To know the growth of each stage, the differences between two consecutive measurements of the diameter of all buds at each stage were averaged. All data of the growth were then calculated their means, standard deviations, and coefficient variations. The coefficient variation of each stage was the percentage of its standard deviation to the mean value.

Because the bud growth followed the exponential model or J-shape (Hidayati et al. 2000; Meijer 1958; Nais 2001), the exponential equation was used to construct a mathematical model for bud's growth. The following equation was applied to construct a model showing a relationship between age or time (day) and bud diameter $(\mathrm{cm}) . \mathrm{Y}_{\mathrm{t}}=\mathrm{c} \mathrm{e}^{\mathrm{k} \mathrm{X}}$, where $\mathrm{Y}_{\mathrm{t}}, \mathrm{c}, \mathrm{e}, \mathrm{k}$, and $\mathrm{X}$ respectively explained bud's diameter at $\mathrm{t}$, constant value, the base value for natural $\log (\ln , 2.719)$, constant value expressing bud's growth rate, and time required to reach a certain diameter (Susatya 2011). To calculate the constants, c, and $\mathrm{k}$, the exponential equation was transformed into the linear model through converting diameter and time values by natural logarithm $(\ln )$, and then run it into regression analysis.

The model was developed into two steps, and used to estimate the time (age) of a bud according to its diameter from all visible stages (Susatya 2011). The first step was to select buds representing the Rafflesia's life history from the smallest diameter (copule stage) to a diameter just before blooming (perigone stage), then followed their cohorts, and measured their diameters every two weeks for six months. Buds were tentatively grouped according to their size categories, respectively representing the smallest, small, medium, large, and largest categories. The range of recorded diameter data for six months was respectively from $0.580 \mathrm{~cm}$ to $1.145 \mathrm{~cm}$ (smallest), $1.580 \mathrm{~cm}$ to 2.300 $\mathrm{cm}$ (small), $2.395 \mathrm{~cm}$ to $5.552 \mathrm{~cm}$ (medium), $5.68 \mathrm{~cm}$ to $10.986 \mathrm{~cm}$ (large), and $9.050 \mathrm{~cm}$ to $22.4 \mathrm{~cm}$ (largest). The largest bud was $22.4 \mathrm{~cm}$, which was a diameter of $R$. arnoldii just before flowering. The second step was to develop a series of regression models to estimate the age of a certain bud at each category according to its corresponding diameter. The results of the estimation, containing all data of diameter and its corresponding estimated age from all size categories, were then used to develop the growth model. The growth model further was employed to estimate time (age) of each development stage according to its diameter range. In addition to the age of each visible stage, to reconstruct the complete life history of $R$. arnoldii, it required to know the time to reach fruit maturity and the time for a seed to inoculate, germinate, and grow within the host plant. For these purposes, information from Meijer (1997) and Hidayati et al. (2000) was used to determine those times.

\section{RESULTS AND DISCUSSION}

\section{The growth of flower bud and the life history of Rafflesia arnoldii}

Not many studies on the life history of Rafflesia species are available, even though it is essential for conservation purposes (Hidayati and Walck 2016). The first study on life history was conducted by Meijer (1958), who collected composite data from different bud sizes of $R$. arnoldii and then followed their fates for a certain time, not the whole life. A similar approach was then used to study the life history of $R$. patma (Hidayati et al. 2000). It was Nais (2001) who observed the cohort of buds from their emergences to anthesis for $R$. keithii, $R$. pricei, and $R$. tengku-adlinii. Furthermore, Both Hidayati et al. (2000) and Nais (2001) divided life history into 7 sequential stages. However, Meijer (1958), Hidayati et al. (2000), and Nais (2001) did not study more detail on the growth and mortality of buds at each stage. Since the only visible structure of Rafflesia is flower buds, which is also subjected to external environments and varies in their sizes, then it is expected that buds of each stage will show different growth and mortality.

Table 1 showed the mean growth rate $\left(\mathrm{cm} \mathrm{day}{ }^{-1}\right)$, standard deviation, and coefficient variations of buds at different development stages. The visible bud of $R$. arnoldii was categorized into 6 development stages consisting of copule, copule-bract transition (CBT), bract, bract-perigone transition (BPT), perigone, and anthesis stages. Anthesis occurred once during the observation at bud's diameter of $22.40 \mathrm{~cm}$. The results of the analysis showed that the diameter range of copule, $\mathrm{CBT}$, bract, BPT, and perigone stages respectively was $0.58-3.03 \mathrm{~cm}, 3.04-6.97 \mathrm{~cm}, 6.98$ $12.03 \mathrm{~cm}, 12.04-17.56 \mathrm{~cm}$, and $17.57-21.80 \mathrm{~cm}$ (Table 1).

Table 1. The mean of growth and its coefficient variation of the bud diameter according to its stage

\begin{tabular}{|c|c|c|c|}
\hline $\begin{array}{l}\text { Flower development } \\
\text { stage (the range of } \\
\text { diameter of buds) }\end{array}$ & $\begin{array}{c}\text { Growth } \\
\text { mean (cm } \\
\left.\text { day }^{-1}\right)\end{array}$ & $\begin{array}{l}\text { Standard } \\
\text { deviation } \\
\left(\mathrm{cm} \text { day }^{-1}\right)\end{array}$ & $\begin{array}{c}\text { Coefficient } \\
\text { variation } \\
(\%)\end{array}$ \\
\hline $\begin{array}{l}\text { Copule } \\
(0.58-3.03 \mathrm{~cm})\end{array}$ & 0.0143 & 0.0146 & 104.059 \\
\hline $\begin{array}{l}\text { Copule-Bract } \\
\text { transition } \\
(3.04-6.97 \mathrm{~cm})\end{array}$ & 0.0435 & 0.0271 & 64.664 \\
\hline $\begin{array}{l}\text { Bract } \\
(7.98-12.03 \mathrm{~cm})\end{array}$ & 0.0572 & 0.0622 & 111.320 \\
\hline $\begin{array}{l}\text { Bract-perigone } \\
(12.04-17.56 \mathrm{~cm})\end{array}$ & 0.1357 & 0.0735 & 54.686 \\
\hline $\begin{array}{l}\text { Perigone } \\
(15.57-21.89 \mathrm{~cm})\end{array}$ & 0.1841 & 0.1276 & 69.731 \\
\hline
\end{tabular}


The mean growth rate of bud diameters varied across the stages, where the copule stage showed the lowest rate $\left(0.0143 \mathrm{~cm} \mathrm{day}^{-1}\right)$, meanwhile the perigone stages exhibited the highest value $\left(0.1841 \mathrm{~cm} \mathrm{day}^{-1}\right)$. This showed that buds at smaller stages exhibited slower diameter growth rates than that of larger stages. The slower growth rate at a smaller diameter of flower buds was also observed at $R$. patma (Hidayati et al. 2000). Buds at both copule and bract stages also had the highest coefficient variations, while those at the other three stages showed much lower coefficient variations. This indicated that buds at earlier stages of the development showed higher growth variations than that of the later stages. The comparison among the mean diameter growth rates of buds across stages displayed that the growth of flower buds followed the exponential model (Table 1). The exponential growth was also mentioned by Hidayati et al. (2000), Meijer (1958), and Nais (2001). The exponential growth was also confirmed by the result of the analysis of the growth model. The result of the analysis of the growth model of flower bud was $\mathrm{Y}=$ $0.785 \mathrm{e}^{0.0052 \mathrm{X}}$ and its coefficient of determination $\left(\mathrm{R}^{2}\right)$ was 0.92 . This result also indicated that the growth model showed a strong relationship between the diameter of bud $(\mathrm{Y})$ and time required to reach the diameter $(\mathrm{X})$. It meant that the model could be used to estimate the age of a flower bud from its diameter.

The information on the diameter range of each stage (Table 1) and the growth model was used to estimate the age of the diameter of buds, and later to reconstruct the life history. The growth development of Rafflesia's bud was not in a discrete pattern, where one stage was replaced completely by the next stage. It consisted of a series of overlapping development stages, where before one stage was complete, the following stage had already developed (Meijer 1997). This was a basic reason why transition stages were introduced in this research. The first visible structure was copule, which was basically the bark of the host plant covering the true Rafflesia structure (Mat-Salleh 1991; Meijer 1997; Nais 2001). The first visible $R$. arnoldii at Taba Penanjung had the diameter range from 0.58-3.03 $\mathrm{cm}$. The start of the development of the inner structures of Rafflesia was still unknown, but the result of examining a dead bud of $R$. arnoldii $(6 \mathrm{~cm}$ in diameter) showed that inner structures such as column, disc, processes, perigone lobes, and bracts had already developed (Figure 2). It was predicted that all these inner structures began to develop in the cupule stage.

The remnant cupule was still be seen through bract, perigone stages, and mature fruits at the base of the bud. As the bud grew, the upper cupule started to crack to allow the first true structure of Rafflesia or bract to be visible. Bract was originally ivory white, but turned black as it grew older. Bract consisted of three series of 5 imbricate and whorl scales (Meijer 1997). From copule to fully developed bract, it required 231 days to 351 days (Figure 3). Bract was gradually replaced by light orange perigone lobes, when it started to drop. The fully developed perigone stage consisted of buds with diameter of $17.57 \mathrm{~cm}$ to $21.89 \mathrm{~cm}$, and was reached in 109 days to 145 days from bract stage. It further took 339 days to 497 days for a small copule of flower bud of $R$. arnoldii to reach anthesis (Figure 3). This appeared to be similar with $R$. keithii, which reached its anthesis in 360-480 days (Nais 1997). Both R. arnoldii and R. keithii were considered to have a similar size of their flowering buds (Meijer 1997). However, it was a quite longer than the smaller sizes of flowering Rafflesia such as $R$. patma, $R$. tengku-adlinii, and $R$. pricei. To reach anthesis, those three species respectively took 221 days (Hidayati et al. 2000), 270 days to 390 days, and 300-450 days (Nais 2001). Fully Orange perigone lobes of bud marked anthesis to occur within 4-5 days. Anthesis took place when a bud reached $22.4 \mathrm{~cm}$. Field observation showed that if the upper layer of the perigone lobe was slightly raised, then the anthesis would take place within 12 days, and lasted between 5 to 7 days. All flower structures decomposed within a month after flowering. Column was the only female structure that did not be decomposed and further developed into mature fruit within 6-8 months (Meijer 1997; Hidayati et al. 2000). Seeds appeared to have high viability, where the seed viability of $R$. arnoldii and $R$. patma respectively reached up to $78.75 \%$ and $93.24 \%$ (Latifah et al. (2017). It was still unknown how seed inoculated to the host plant. However, it was estimated that seed inoculation and germination within the host plant required between 2 and 3 years (Meijer 1997; Hidayati et al. 2000). Overall, the complete life history of female R.arnoldii was estimated between 3 years and 5 months and 5 years and one month, while male $R$ arnoldii needed a shorter time and only required between 2 years and 11 months to 4 years and 5 months. These estimated values were within the range of the life history predicted by Meijer (1958), who estimated 4.5 to 5 years for $R$. arnoldii to complete its life history (Figure 3 ).

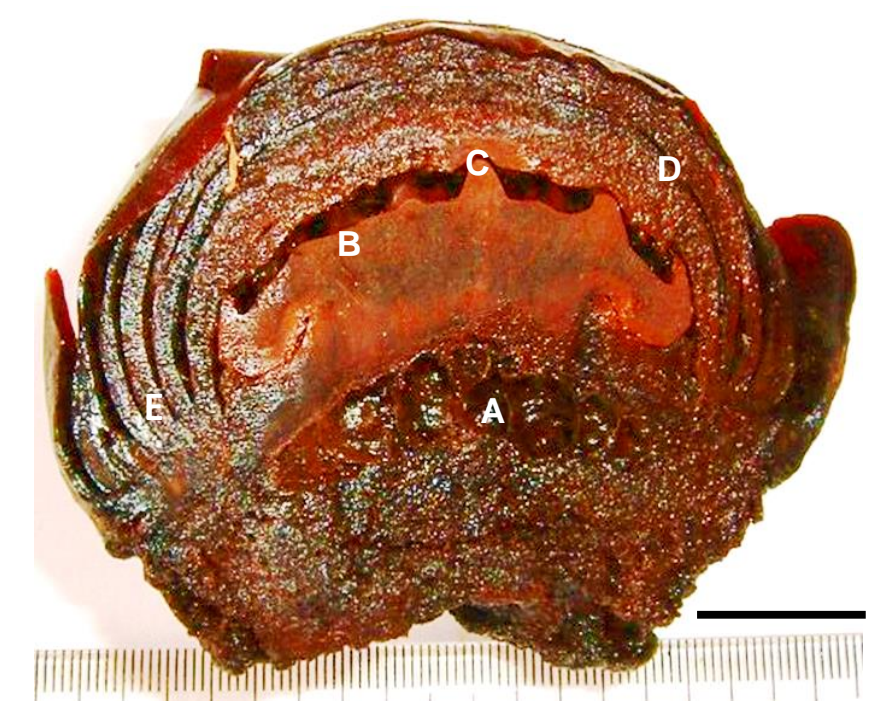

Table 2. The inner structures of Rafflesia arnoldii at a small flower bud (6 cm diameter). A. Column. B. Disc. C. Processes. D. Perigone lobes. E. Bracts. Bar $=2 \mathrm{~cm}$ 


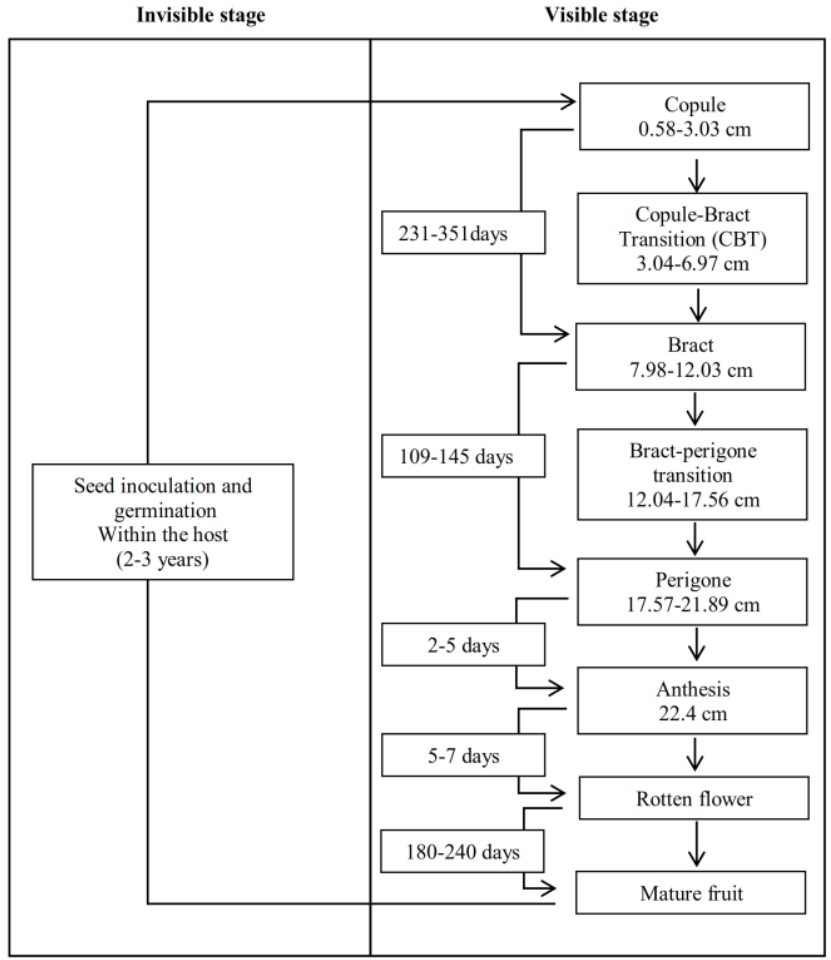

Figure 3. The result of the reconstruction of the complete life history of $R$. arnoldii

\section{The population structure of $\boldsymbol{R}$. arnoldii}

The population of species of $R$. arnoldii seems to be small compared to the other higher plants. Susatya (2011) and Susatya et al. (2017) founds that the average population size of $R$. arnoldii was only 12.5 flower buds. The population size of $R$. arnoldii at the research site (17 flower buds) was slightly higher than its average population size. The small population size was also reported at the other species of Rafflesia such as $R$. kerrii Meijer (Lau 2003), $R$. manillana Teschem., $R$. schadenbergiana Gopp., $R$. speciosa Barcelona et Fernando (Barcelona et al. 2009), R. cantleyi Meijer
(Munirah 2017), and R. bengkuluensis Susatya, Arianto et Mat-Salleh (Susatya et al. 2017).

The initial observation showed that the total population reached up 17 flower buds and belonged to only copula, CBT, and bract stages. Larger stages such as BPT and perigone contained no buds. The initial population structure was dominated by buds belonging to CBT. Buds at CBT reached up to $58.82 \%$ of the total buds. Meanwhile, buds at copule and CBT were fewer (Figure 4a). Within 3 months, the population structure was significantly changed due to mortality, new recruitment, and growth a bud from a stage to the next growth development stages. The population structure of this period was shifted toward to both copule and bract stages (Figure 4b). During these 3 months observation, 4 buds belonging to CBT died, but 5 new bud recruitments emerged, which automatically belonged to the copule stage. It was interesting that after 3 months the pattern of population structure appeared to be opposite to the previous one. The dominant CBT structure at the initial observation became the least dominant, while less dominant copule and bract stages at the initial observation developed into the dominant ones. Of the 18 flower buds at the second observation, both copule and bract stages contributed to $44.44 \%$ of the total buds, while BCT only had $5.5 \%$ (Figure $4 \mathrm{~b}$ ). During this period, it was also noted the emergence of the bract-perigone transition stage (BPT), which consisted of $5.56 \%$ of the total buds. This was due to the growth of a bud from bract stages into BPT. After 6 months of observation, the population structure showed a different pattern and appeared to be a better structure than those of the two previous observations. Within this period, the population structure consisted of all growth stages. Unlike the two previous observations, this last observation showed that no stage was distinctively more dominant than the others. In this last observation, perigone stage interestingly became the emerging category to shape the population structure. Three factors such as the loss of buds ( 7 buds), low new recruitment ( 2 buds), and an incident of flowering Rafflesia had attributed the change of the last population structure of $R$. arnoldii (Figure 4.C).
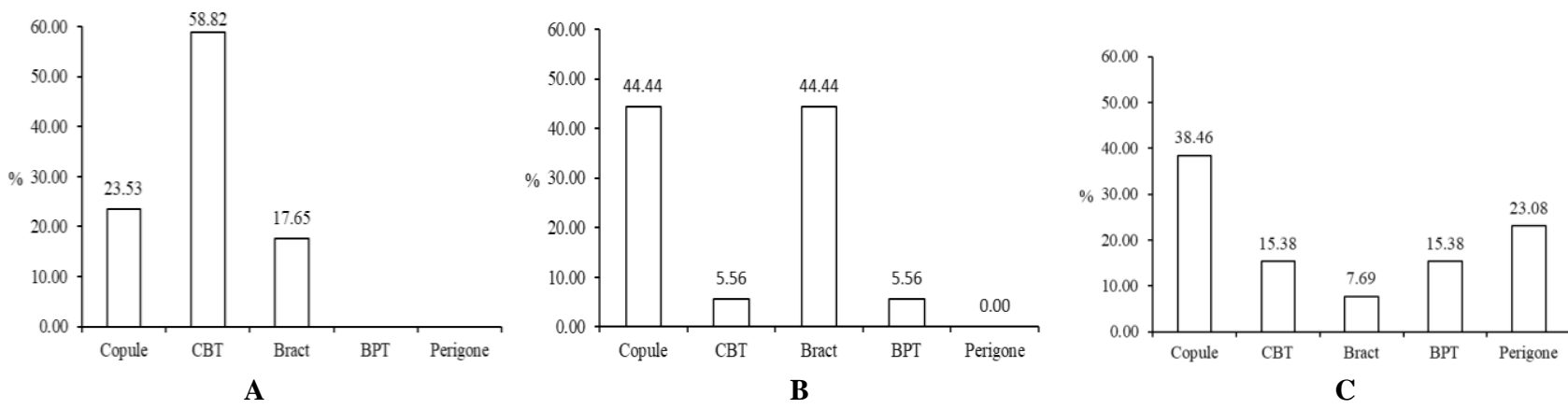

Figure 4. The population structure of Rafflesia arnoldii according to its flower bud growth development stage. A. The population structure at the initial, B. After 3 months, and C. After 6 months observations. CBT and BPT respectively referred to copule bract transition and bract perigone transition stages. 


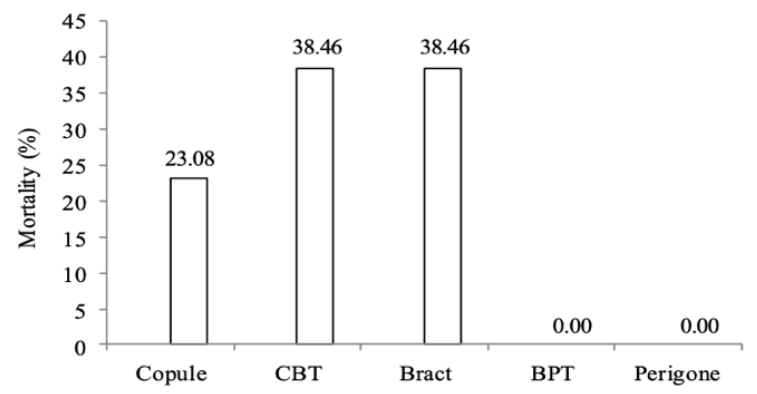

Figure 5. The bud mortality of Rafflesia arnoldii according to its growth development stage

Total buds died during the six months observation reached up to 11 buds or $47.82 \%$ of all recorded buds. However, in the same period, the recruitment was only recorded 7 buds. This was the first time the bud recruitment was recorded for the species of Rafflesia. Comparison between the high mortality and low recruitment of buds of $R$. arnoldii indicated an alarming signal concerning the future population of $R$. arnoldii. The mortality of $R$. arnoldii was far less than that of $R$. patma and $R$. bengkuluensis. Rafflesia patma and $R$. bengkuluensis respectively suffered the loss of $75 \%$ of its buds (Hidayati et al. 2000), and 67\% (Susatya et al. 2017). Sofiyanti et al. (2007) summarized that the mortality of Rafflesia's buds generally varied from $60 \%$ to $90 \%$. The cause of bud's mortality was not further observed in this research. However, Hidayati et al. (2000) provided information on the cause of

mortality. They reported that bud's mortality was caused by the predations from the squirrel, and the injured parts of flower buds were immediately followed by a rotting process that led to the bud's mortality. Detailed analysis of the bud's mortality showed an interesting pattern, where all losses occurred at buds belonging to copule, CBT, and bract stages. Among these three stages, buds at both CBT and bract stages showed the highest mortality rates $(38.46 \%)$ (Figure 5). Meanwhile, the larger buds at both BPT and perigone stages were not recorded any losses. This pattern indicated that smaller sizes of buds showed high mortality, meanwhile larger size survived better (Susatya et al. 2017).

In conclusion, the exponential growth of buds of $R$. arnoldii was confirmed in this research. The growth rate of buds at copule stage was far slower than those of bract and perigone stages. The life history of $R$. arnoldii was reconstructed based on the growth model of its flower buds. It was estimated that the female flowers of R.arnoldii respectively took from 3 years and 5 months to 5 years and one month to complete its life history. The male flower took a shorter time, and needed 2 years and 11 months to 4 years and 5 months to reach its complete life history. The population structure of $R$. arnoldii was dynamically changed in a short period of time and mainly caused by the combination between the low recruitment and high mortality of buds. Rafflesia arnoldii experienced high mortality rates at copule, copule-bract transition, and bract stages. Buds at bract-perigone transition and perigone stages had very high survivorships and likely would undergo anthesis.

\section{ACKNOWLEDGEMENTS}

The author was indebted to Toi, Tri Hartoyo, who helped to carry out the field observation, and to Siti Nur Hidayati, who made comments on the manuscript. The author was also very grateful for Astri Sri Wahyu Utami, Sequoia Mohammad Satrio Rhomadhon, and Magnolia Gina R. Satriorini who helped to provide logistics and support during field observations and manuscript preparations.

\section{REFERENCES}

Barcelona JF, Pelser PB, Ballete DS, Co LL. 2009. Taxonomy, ecology, and conservation status of Philippine Rafflesia (Rafflesiaceae). Blumea 54.2009: 77-99.

BPS Kab. Kepahiang. 2018. Kabupaten Kepahiang dalam angka. Badan Pusat Statistik Kepahiang. PNRI, Kepahiang.[Indonesian].

Crawley MJ. 1986. Life history and environment. In: Crawley MJ (ed.). Plant Ecology. Blackwell Scientific Publication, Boston.

Horvits CC, Schemske DW. 2002. Effects of plant size, leaf herbivory, local competition and fruit production on survival, growth, and future reproduction of a neotropical herb. J Ecol 90: 279-290.

Hidayati SN, Meijer W, Baskin JM, Walck JL. 2000. A contribution to the life history of the rare Indonesian holoparasite Rafflesia patma (Rafflesiaceae). Biotropica32 (3): 408-414.

Hidayati SN, Walck JL. 2016. A review of the biology of Rafflesia what we do know and what's next?. Bulletin Kebun Raya 19 (2): 67-78.

Lau KH. 2003. Taburan dan biologi Rafflesia kerrii Meijer di Kelantan. [Hon. Thesis]. Universiti Kebangsaan Malaysia, Malaysia. [Malay].

Latifah P, Riswati MK, Houdin E, Wawangningrum H. 2017. Viability test on the seeds of $R$. arnoldii $\mathrm{R}$. Br. and $R$. patma Blume. Bulletin Kebun Raya 20 (1): 25-32.

Lime JM. 2017. Adaptive Strategies: Growth and Life Forms. Chapt. 4-5. In: Glime JM (ed.) Bryophyte Ecology. Volume 1. 4-5-1-4-5-23. Physiological Ecology. Michigan Technological University and the International Association of Bryologists.

Lind EM, Borer E, Seabloom E, Adler P, Bakker JD, Blumenthal DM, Crawley M, Davies K, Firn J, Gruner DS, Harpole WS, Hautier Y, Hillebrand H, Knops J, Melbourne B, Mortensen B, Risch AC, Schuetz M, Stevens C, Peter DW. 2013. Life-history constraints in grassland plant species: a growth-defense trade-off is the norm Ecol Lett 16: 513-521.

Mat-Salleh K. 1991. Rafflesia, magnificent flower of Sabah. Borneo Publishing Company, Kota Kinibalu.

Meijer W. 1958. A contribution to the taxonomy and biology of Rafflesia arnoldii in West Sumatra. Annales Bogorienses 3 (1): 23-44.

Meijer W. 1997. Rafflesiaceae. Flora Malesiana Ser. 1: 1-42.

Munirah SN. 2017. Distribution and conservation of Rafflesia in northern Peninsular Malaysia. $7^{\text {th }}$ International Flora Malesiana Symposium. 17-22 June 2017. Leiden, Netherland

Nais J. 1997. Distribution, reproductive ecology and conservation of Rafflesia in Sabah. [Disertation]. University of Aberdeen, Aberdeen, UK.

Nais J. 2001. Rafflesia of the world. Sabah Park in association with Natural History Publications (Borneo) Sdn. Bhd., Kota Kinabalu

Smith RL. 1986. Elements of Ecology. Harper \& Row Publishers. New York.

Sofiyanti N, Mat-Salleh K, Purwanto D, Syahputra E. 2007. The note on morphology of Rafflesia hasseltii Surigar from Bukit Tiga Puluh National Park, Riau. Biodiversitas 9 (1): 257-261. 
Susatya A. 2011. Rafflesia: Pesona Bunga Terbesar di dunia. Direktorat Kawasan Konservasi dan Bina Hutan Lindung. Departemen Kehutanan RI, Jakarta. [Indonesian]

Susatya A. Prandeka F, Saprinurdin S, Nasrulrahman. 2017. Population Dynamics of the very rare Rafflesia bengkuluensis at Padang Guci Valley, Kaur Regency, Southern Bengkulu. Bot Gard Bull 20 (1): 4350
Wunder J, Brzeziecki B, Zybura H, Reineking B, Bigler C, Bugmann H. 2008. Growth-mortality relationships as indicators of life history strategies: a comparison of nine tree species in unmanaged European forests. Oikos 117: 815-828.

Zuhud AM, Hikmat A, Jamil N. 1998. Rafflesia Indonesia: Keanekaragaman, ekologi dan pelestariannya. Yayasan Pembina Suaka alam dan Suaka Margasatwa Indonesia \& Laboratorium Konservasi Tumbuhan, IPB, Bogor. [Indonesian]. 